\title{
Avaliação da Aprendizagem: o portfólio como auxiliar na construção de um profissional reflexivo
}

\author{
FÁTIMA MARIA DE FREITAS ALBERTINO \\ Mestre em Educação, professora do Centro Universitário Filadélfia, integrante do \\ Grupo de Pesquisa de Diagnóstico de Enfermagem - USP/SP \\ fatimaalbertino@uol.com.br \\ NADIA APARECIDA DE SOUZA \\ Doutora em Educação, professora da Universidade Estadual de Londrina, \\ integrante do Núcleo de Estudos e Pesquisas em Avaliação Educacional \\ nadia@uel.br
}

\begin{abstract}
Resumo
O presente trabalho teve como preocupação superar práticas avaliativas que pouco contribuem para a formação do profissional de enfermagem comprometido com o desvelamento, reflexão e superação das dificuldades do cotidiano de trabalho. Assim, houve necessidade de melhor compreender como uma nova prática avaliativa altera uma concepção anterior e interfere na formação do futuro profissional. Para tanto, desenvolveuse estudo qualitativo, envolvendo 21 alunos da disciplina Administração da Assistência de Enfermagem. A coleta de dados "utilizou" diferentes instrumentos: representação simbólica, questionários, portfólio, fichas de análise de desempenho, observação direta do cotidiano e grupos de discussão para análise dos aspectos a serem aperfeiçoados no desempenho profissional. As análises evidenciaram que a avaliação como processo gerou maior comprometimento com a reflexão sobre a prática e o aperfeiçoamento do processo de trabalho e com a superação das questões emersas do cotidiano. Pelos resultados obtidos é possível afirmar que o medo progressivamente desaparece quando a avaliação efetivada prioriza o processo e não apenas o produto, que a avaliação como processo é fator importante na relação entre o ensino e a aprendizagem e que a relação horizontal entre professor e aluno contribuiu para a formação de um profissional instrumentalizado criticamente para a tomada de decisões.

Palavras-chaves: avaliação da aprendizagem, ensino superior, concepção e ação docente, portfólio.
\end{abstract}

\section{Resumen}

Este trabajo tuvo como objetivo superar prácticas evaluativas que contribuyen poco para la formación del profesional de enfermería, comprometido con el desvelamiento, reflexión y superación de las dificultades cotidianas en el trabajo. Así, se hizo necesario comprender mejor cómo una nueva práctica evaluativa altera una concepción anterior e interfiere en la formación del futuro profesional. Para ello, se desarrolló un estudio cualitativo, incluyendo 
21 alumnos de la asignatura Administración de la Asistencia de Enfermería. La recolección de datos "utilizó" diferentes instrumentos: representación simbólica, cuestionarios, portafolio, fichas de análisis del desempeño, observación directa de la rutina diaria y grupos de discusión para el análisis de los aspectos a mejorar en el desempeño profesional. Los análisis evidenciaron que la evaluación como proceso generó un mayor compromiso con la reflexión sobre la práctica y la mejoría del proceso de trabajo y con la superación de las cuestiones surgidas en lo cotidiano. Por los resultados obtenidos es posible afirmar que el miedo desaparece progresivamente cuando la evaluación realizada prioriza el proceso y no apenas el producto, que la evaluación como proceso es un factor importante en la relación entre la enseñanza y el aprendizaje y que la relación horizontal entre profesor y alumno contribuyó para la formación de un profesional preparado para tomar decisiones de modo consciente y con visión crítica.

Palabras-clave: evaluación del aprendizaje, enseñanza superior, concepción y acción docente, portafolio.

\begin{abstract}
The main concern of this study was to overcome evaluative practices that add little to the formation of the nursing professionals committed with unveiling, reflecting and overcoming the difficulties of their daily work routine. Thus, it was necessary to better understand how a new evaluation practice alters a previous conception and interferes in the formation of new professionals. For this reason, a qualitative study was developed, involving 21 students from the Nursing Assistance Administration course. For the collection of data different instruments were "used": symbolic representation, questionnaires, portfolios, performance analysis cards, direct observation of daily activities and discussion groups for the analysis of the aspects to be improved in the professional performance. The analyses showed that evaluation as a process generated a higher level of commitment to reflecting on the practice and improvement of the work process and to overcoming issues arising in the daily routine. The results obtained allow us to state that fear gradually disappears when evaluation prioritizes the process and not only the product, that evaluation as a process is an important factor in the relation between teaching and learning and that the horizontal relationship between teacher and learner contributed to the formation of a conscious and critically wellprepared professional to make decisions.
\end{abstract}

Key words: learning evaluation, higher education, teacher conception and action, portfolio. 
"Dói a história, dói o esforço, dói a mudança. A dor já não é sofrimento, é uma cáustica virtude imposta pelo roteiro da vida. O existir raspa na pele como a lixa na pedra. E o tempo acaba por não distinguir: qual a mais áspera, a existência ou a lixa? Qual a mais resistente, a pele ou a pedra?" (Pecci, 1986, p. 147)

O homem é avaliado desde que nasce, das mais diversificadas formas e de acordo com os mais variados objetivos e, assim, a avaliação vai se tornando, a cada dia, um meio que possibilita mais e mais contemplar o passado para orientar a compreensão do presente e a delimitação do futuro.

Quer na vida, quer na escola, avaliar não se configura uma tarefa simples ou fácil, principalmente porque deve proporcionar uma reflexão geradora de mudanças, superações, crescimento, evolução; facultando que educador e educando busquem novas possibilidades de aprendizagem e de desenvolvimento pela progressiva e constante construção e reconstrução de conhecimentos, respeitando a diversidade de vozes presentes no dia-a-dia escolar; predispondo-se o educador a considerar o potencial de cada aluno, orientando-o rumo ao seu pleno desenvolvimento.

É preciso que o aluno seja avaliado com justiça e assim possa ser orientado e estimulado, em uma perspectiva de superação permanente dos próprios limites e de aperfeiçoamento constante das próprias possibilidades. Portanto, é preciso implementar uma avaliação que, afastando-se da mera classificação, permita a análise da aprendizagem efetivada e a reorganização do processo de ensino, favorecendo a reflexão, a crítica e a expressão de idéias.

Para tanto, é fundamental aproximar-se da realidade do aluno, estar voltado para a transformação, para o crescer e renascer de todos, alunos e professores; para superar a perspectiva do professor controlador do incontrolável, com sistematizações elaboradas fora da complexidade que caracteriza e condiciona a realidade local; para realizar uma avaliação que estimule a criatividade do aluno e desenvolva sua capacidade de pensar e de trabalhar de forma independente, tendo autocontrole sobre sua aprendizagem; para refletir sobre o significado e a função da avaliação na (re)construção de "um educador que se preocupe com sua prática educacional" comprometendo-a, com a transformação que progressivamente se afasta do "agir inconscientemente e irrefletidamente" (Luckesi, 1997, p. 78).

A escola compõe um espaço social em que acontecem mudanças, em 
que se estabelecem e re-estabelecem relações, se constroem e reconstroem conhecimentos, valores e atitudes e que, portanto, exige daqueles que nela interagem a superação da concepção emersa de um cotidiano apático, passando à concepção de um cotidiano exposto a múltiplas e variadas influências, resistências e contradições.

Destarte, "se a avaliação é dentre os elementos que constituem o processo de ensino, aquele que melhor retrata uma concepção teórica de educação e que, por sua vez, melhor traduz uma concepção teórica de sociedade" (Sordi, 1995, p. 14), torna-se fundamental conciliar a teoria proclamada com a prática executada, assegurando a verificação de soluções e aperfeiçoamentos no decorrer dos processos de ensino e aprendizagem.

Considerando que esse processo pode afigurar-se como um "jogo", necessário se faz que educador e educando tenham bem claras as regras que o orientam. Assim, da concepção à ação, os princípios e fundamentos que direcionam o educador precisam estar claramente delimitados.

Avaliar não é um mero momento dos processos de ensino e aprendizagem, mas é uma ação conseqüente, pois implica um juízo valorativo que expressa a qualidade do objeto, obrigando, conseqüentemente, a um posicionamento efetivo sobre o mesmo (Luckesi, 1997). Abrangendo todos os componentes que integram o cotidiano da escola, a avaliação necessita ultrapassar os aspectos técnicos e voltar-se para a compreensão dos muitos e variados fatores que facilitam ou dificultam a (re)construção do saber pelo educando e lhe possibilitam a reflexão e a superação das dificuldades vivenciadas.

São muitos os campos de intervenção de enfermagem, diversos os palcos, diferentes os teatros e muitas as peças; o futuro profissional atua no atendimento primário, secundário e terciário; em unidades básicas de saúde, creches, igrejas, escolas, hospitais de pequeno e grande porte, dentre outros. $\mathrm{O}$ estudante participa de inúmeros ensaios por quatro anos, com sonhos de dominar a teoria, de concretizá-la e, porque não, transformá-la, então, todos os dias, em sua prática profissional.

No decorrer desse período acadêmico o aluno vai adquirindo conhecimentos, trocando experiências e, ainda, realizando atividades que possibilitem a verificação do conteúdo apreendido, do desenvolvimento atingido, do potencial de criatividade alcançado e, ainda, do seu comprometimento profissional.

No último ano, quando a construção do processo de formação acadêmica está quase em seu final, em Administração da Assistência de Enfermagem, disciplina conclusiva, o aluno tem a oportunidade de atuar como protagonista, junto com o enfermeiro que coordenar a unidade onde realiza o estágio, de colocar em prática todas as habilidades e competências 
desenvolvidas no decorrer do curso e de desenvolver a gerência da assistência de enfermagem. Nesse espaço e tempo, há uma troca de experiências e de conhecimentos entre a equipe de enfermagem e o futuro enfermeiro e, gradativamente, este vai ampliando sua ação, agindo e interagindo junto ao grupo de profissionais da unidade.

Orientando a cena, o professor - diretor - conduz, direciona e coordena as atividades do aluno, visando facultar-lhe a articulação de seus muitos saberes com as demandas que emanam do cotidiano de atuação profissional. Por isso, inúmeras vezes ele entra em cena e atua junto ao aluno.

É importante ressaltar que, nesse palco, o trabalho realizado envolve pessoas, geralmente com enfermidades que apresentam diferentes graus de gravidade, exigindo dos alunos, que começam a conquistar o seu espaço, o desenvolvimento de habilidades manuais; de pensamento científico, reflexivo e crítico, na realização de condutas que possam manter a vida ou ampliar o bem-estar do paciente em situações de emergência ou urgência, de forma humana e ética.

Nesse momento, em que teoria e prática efetivamente se congregam, o processo de avaliação se afigura fundamental para o aperfeiçoamento do futuro profissional e, portanto, para a progressiva superação dos problemas e dificuldades de formação ainda presentes.

Existem, nesse palco - espaço de ensino e aprendizagem, de aprofundamento teórico e de vivência prática - diferentes instrumentos que direcionam a avaliação. Nesse período de formação, os instrumentos não só enfocam responsabilidade, desempenho profissional, habilidades técnicas, espírito crítico, como também favorecem, em decorrência de seu formato e maneira de viabilização, a promoção de espaços para comentários e para o estabelecimento de compromissos a serem assumidos por professores e alunos.

A dificuldade dos professores em avaliar os alunos e a destes - os alunos - em compreender as possibilidades e dificuldades do processo experienciado em decorrência do simples conhecimento dos resultados explicitados pela avaliação é imensa. Nós, professores, realizamos avaliações classificatórias - valendo-nos de provas e testes meramente constatatórios - nos blocos teóricos, aparentemente, sem maiores dificuldades, mas não temos preparo suficiente para promover avaliações comprometidas com a compreensão do processo e com a superação das dificuldades, quer nos blocos teóricos, quer, principalmente, no campo de estágio. Superar a perspectiva classificatória na construção de uma avaliação diagnóstica e, portanto, preocupada com o re-direcionamento do futuro, constitui fonte de conflito, uma vez que, apesar de se buscarem 
"formas alternativas para aperfeiçoá-la, humanizá-la, [...] a ênfase ainda é tecnicista" (SORDI, 1995, p. 19).

No decorrer do estudo, foi possível registrar algumas inquietações que se interpuseram no contato com os alunos, na discussão com professores e na análise das práticas avaliativas implementadas.

1. Como uma prática que suscita medo e ansiedade pode contribuir para o crescimento e aperfeiçoamento do aluno e do profissional?

2. De que forma uma prática que faz crescer a insegurança pode contemplar a formação de competências, habilidades e atitudes dos profissionais que estavam sendo preparados?

3. De que maneira uma avaliação centrada no produto pode contribuir para o aperfeiçoamento dos processos de ensino e aprendizagem?

4. Quais as mudanças a serem implementadas no processo de avaliação visando garantir uma evolução progressiva de sua prática em direção a uma concepção diagnóstica/formativa?

É fundamental que o futuro profissional aprenda a utilizar os dados emergentes da avaliação na superação dos problemas que aparecem no diaa-dia de trabalho, uma vez que "é através das interações que acontecem no campo da prática, que se desenvolve a imagem que a aluna tem de enfermagem e do papel de enfermeira" (Angelo, 1989, p. 119).

Assim, a avaliação - para professores e alunos - deve favorecer a evolução técnico/científica, deve ampliar os vínculos de solidariedade e comprometimento entre todos que vivenciam o mesmo momento, deve permitir que cada um, consciente dos próprios limites, se comprometa com a ampliação de possibilidades de um fazer mais competente, que repercuta naturalmente na valorização do cuidar e, por conseqüência, na qualidade de vida das pessoas cuidadas, pois

"a formação de um profissional requer clareza quanto ao conjunto de ações que determinam o exercício competente da profissão. Assim sendo, os dados relevantes não são do foro intimo de cada professor. Eles estão atrelados à necessidade do desempenho profissional histórica e contextualmente determinados." (Kestenberg, 1985, p. 105)

Nessa perspectiva, a preocupação em superar as práticas avaliativas que pouco contribuem para a formação do profissional comprometido com a reflexão e desvelamento de seu cotidiano, com a conseqüente superação das dificuldades com as quais se depara, suscitou a necessidade de refletir 
sobre o seguinte problema: como uma prática avaliativa diferenciada altera uma concepção de avaliação anterior e interfere na formação do futuro profissional de enfermagem?

Responder a este questionamento pressupõe compreender os processos por meio dos quais um novo fazer avaliativo introduz alterações que suscitem o desenvolver progressivo e contínuo do profissional reflexivo e comprometido com o seu aperfeiçoamento.

Todavia, na construção da resposta a esse problema, pela consecução do objetivo estabelecido, muitas ações se fizeram necessárias:

1. determinação da percepção do estudante de enfermagem em relação ao processo de avaliação e suas finalidades;

2. realização de reflexão sobre as práticas avaliativas implementadas e sua relação com a formação do profissional;

3. realização de mudanças na sistematização da avaliação da disciplina, viabilizando um aperfeiçoamento dos processos de ensino e aprendizagem e, ainda, favorecendo um maior desenvolvimento do referencial e do espírito crítico do aluno;

4. proposição de novos instrumentos de avaliação que contemplem pontos relevantes e que possibilitem ao educando refletir sobre os seus saberes para a melhoria de suas habilidades e competências.

A implementação de uma prática avaliativa voltada para a formação de alunos conscientes de suas potencialidades e dificuldades, comprometidos com o aperfeiçoamento progressivo e capazes de superar os problemas que surgiram no campo de estágio exigiu o compromisso com o aprender e com o transformar.

O caminho escolhido para aumentar a compreensão dos problemas inerentes à formação do profissional de enfermagem e para aprofundar não só os conhecimentos relativos à avaliação, mas também a sua relação com o aperfeiçoamento dos processos de ensino e aprendizagem mediante a ampliação da capacidade de inter-relação entre teoria e prática, foi o da pesquisa qualitativa.

A pesquisa qualitativa possibilitou que a prática avaliativa fosse construída a partir de experiências do passado, associadas às experiências do presente e permitiu, ainda, a edificação de novas práticas - adequadas ao tempo e ao espaço ocupado pelo aluno em campo de estágio. Experiências e práticas que precisavam estender-se e concretizar-se no cotidiano profissional, de forma a garantir que as rotinas de que está impregnado o dia-a-dia não impeçam os enfermeiros de comprometerem- 
se com o próprio aperfeiçoamento, pela reflexão constante de seu fazer em confronto com seu saber.

Participaram do estudo 21 (vinte e um) alunos, do total de 37 (trinta e sete) que compõem o quarto ano do Curso de Enfermagem e que cursaram a disciplina Administração da Assistência de Enfermagem, no ano de 2000. A realização do estudo exigiu a coleta de informações por meio de procedimentos variados: questionários, portfólio demonstrativo e ficha de análise de desempenho.

A análise dos dados coletados no decorrer da pesquisa privilegiou a análise de conteúdos, visto que esta constitui "uma técnica de investigação que tem por finalidade a descrição objetiva, sistemática e quantitativa do conteúdo manifesto da comunicação" (Bardin, 1977, p. 36), ao favorecer uma compreensão mais profunda do sentido da comunicação expressa e das ações empreendidas. A definição das categorias temáticas decorreu da organização dos muitos dados coletados na etapa de pré-análise, após estudos minuciosos que resultaram em agrupamentos organizados por unidades de significação que se apresentaram convergentes.

\title{
AS MUDANÇAS NA AVALIAÇÃO FAVORECENDO A FORMAÇÃO DO PROFISSIONAL REFLEXIVO
}

\begin{abstract}
"Sucesso e fracasso em termos de aprendizagem parecem ser uma perigosa invenção da escola. E verdadeiramente questionáveis os indicadores desses conceitos que tendem a provocar uma oposição entre as práticas avaliativas e o respeito às crianças e jovens brasileiros no seu direito constitucional à educação. Tornar objetivos, precisos e mensuráveis os indicadores de sucesso e fracasso permanece, ainda, como um dos mais sérios intentos de todas as escolas, que negam a individualidade de cada educando em razão de parâmetros avaliativos perversos e excludentes." (Hoffmann, 2000, p. 11)
\end{abstract}

Para Luckesi (1997), a avaliação permite a tomada de decisão para que atos subseqüentes sejam encaminhados. Essa função básica articula-se com as funções de proporcionar a autocompreensão do educando e do educador, motivar o crescimento, aprofundar as aprendizagens e subsidiar a consecução do processo de ensino e aprendizagem.

O cumprimento dessas funções só acontece, verdadeiramente, se o processo implementado, bem como os instrumentos utilizados respeitarem 
os conteúdos essenciais propostos, as habilidades trabalhadas, compatibilizando os níveis de dificuldade ensinados e aprendidos, sendo claros e compreensíveis e tiverem por objetivo principal orientar professores e alunos no encaminhamento do ensinar e do aprender, uma vez que,

"compete, de início, oferecer condições favoráveis para o aluno significar a sua aprendizagem, objetivando gerar competências individuais, ou seja, qualificar o sujeito a pensar, criar, decidir, enfim, tornar-se independente/crítico." (Medeiros, 2001, p. 26)

Assim, seria necessário que a avaliação integrasse os processos de ensino e aprendizagem e estivesse a seu serviço, auxiliando o educando na construção e reconstrução de conhecimentos e favorecendo seu pleno desenvolvimento profissional ao promover condições para que ações sejam revistas e redirecionadas, no sentido de consolidar uma postura mais crítica e inovadora diante das situações que fazem parte do cotidiano profissional.

Todavia, a realidade é complexa. Estamos em um período de transição, em que diferentes lógicas - inclusivas e segregatórias - orientam e determinam a prática avaliativa no contexto escolar: a prática classificatória e o discurso formativo precisam ser (re)significados em prol de uma "utopia promissora" (Hadji, 2001), principalmente considerando que

"a democratização do ensino e a busca de uma pedagogia mais diferenciada fizeram emergir, e depois se difundir, a lógica formativa, de modo que hoje em dia as forças e a legitimidade de ambas estão mais equilibradas. De que lado o futuro fará pender a balança? Ninguém sabe. O momento não é de concluir, e sim de trabalhar para que coexistam e se articulem duas lógicas de avaliação." (Perrenoud, 1999, p. 18)

\section{O PRINCIPIAR DA CAMINHADA...}

Antes de iniciarmos o trabalho, o conteúdo programático da disciplina Administração da Assistência de Enfermagem era ministrado no bloco teórico e a conferência do aprendizado era realizada através de duas provas; durante este bloco, a avaliação era classificatória.

No bloco prático as avaliações se faziam através de discussões, entre professor e aluno e, em três momentos predeterminados, o discente recebia uma nota. No transcorrer do estágio eram cobrados alguns trabalhos relativos aos conteúdos estudados, com a intenção de favorecer o aprendizado. No final da disciplina, as notas eram somadas e divididas para o estabelecimento de uma média final. 
Já era evidente, nessa época, para o grupo de professores, a importância de o profissional construir o seu conhecimento, mas seriam necessárias mudanças para a real efetivação dessa idéia no decorrer do trabalho. As mudanças indispensáveis na forma de estruturação e condução da disciplina, e principalmente no processo de avaliação, envolveram os vários professores - todos dispostos a redirecionar o processo pedagógico.

Nessa perspectiva, a avaliação proposta tinha a intenção de estreitar a convivência entre o aluno e o professor, possibilitando uma experiência didático-pedagógica diferenciada e obter, como resultado, a formação de um profissional capaz de: operacionalizar o seu aprendizado, progredir em sua profissão e, ainda, preparar-se melhor para acompanhar o desenvolvimento da enfermagem no Brasil, até porque

\begin{abstract}
"profissionalizar o indivíduo, ou seja, prepará-lo para a prática profissional, requer do docente a sensibilidade necessária para libertar o aluno da relação de dependência e permitir-lhe a aquisição da autonomia. Tal autonomia o levará a libertar-se dos rituais de poder que dificultam o exercício do pensamento, que the restringem o poder decisório e a capacidade de discernimento, enfim, permitirá a construção do enfermeiro num espaço de cuidado e de educação que possibilite desenvolver a arte de viver (estética de existência) e de conduzir-se por si mesmo." (Geib et al., 1999, p. 89-90)
\end{abstract}

A avaliação traça a trajetória do estudante e do professor, informa suas verdadeiras necessidades, proporciona ajuda pedagógica necessária para a superação de possíveis falhas e, ainda, estimula o desenvolvimento do processo de trabalho, colaborando na formação do profissional comprometido com seu fazer.

\title{
AS ESCOLHAS DA CAMINHADA...
}

O procedimento avaliativo privilegiado para introduzir as transformações necessárias à prática avaliativa foi o portfólio, construído no decorrer de todo o ano letivo.

A introdução de uma prática avaliativa diferenciada levou os alunos a participarem ativamente do processo de ensino e aprendizagem. Em diversos relatos, em resposta a questionários ou em textos que integram o portfólio, o aluno enfatizou que houve crescimento profissional em conseqüência do processo de avaliação implementado. Em campo de estágio o professor observava a atuação do aluno, discutia suas intervenções e orientava estratégias para o alcance dos objetivos propostos. 
Alunos e professores encontravam-se regularmente para refletir criticamente sobre as tarefas executadas e buscar, se necessário, novas estratégias para melhorar o desenvolvimento profissional. Tudo era registrado no instrumento de avaliação e tudo contribuía para que cada um dos envolvidos - professores e alunos - refletisse sobre o evoluir na apropriação do saber e no edificar da prática profissional, principalmente porque a avaliação deve auxiliar o estudante em sua aprendizagem e desenvolvimento, regulando o processo de construção do conhecimento ao otimizar novas aprendizagens, uma vez que:

"pode-se ajudar um aluno a progredir de muitas maneiras: explicando mais simplesmente, mais longa ou diferentemente; engajando-o em nova tarefa, mais mobilizadora ou mais proporcional a seus recursos; aliviando sua angústia, desenvolvendo-lhe a confiança, propondo-lhe outras razões de agir ou de aprender; colocando-o em um outro quadro social, desdramatizando a situação, redefinindo a relação ou o contrato didático, modificando o ritmo de trabalho e de progressão, a natureza das sanções e das recompensas, a parcela de autonomia $e$ de responsabilidade." (Perrenoud, 1999, p. 105)

Inicialmente, para a construção do portfólio, o aluno apresentou o planejamento estratégico e operacional de todas as atividades a serem desenvolvidas durante o caminhar da disciplina - estudos de casos, visitas em instituições de saúde, sistematização da assistência, educação em saúde, educação continuada, técnicas e procedimentos de enfermagem, relatórios de eventos etc - e progressivamente foi anexando as tarefas executadas. Assim, todos os conteúdos programáticos estabelecidos, pelas professoras no início da disciplina, foram sendo cumpridos; todas as tarefas discutidas e negociadas com os alunos, no decorrer da disciplina, foram sendo realizadas.

Constantemente, durante a construção do portfólio, o aluno conversava com a professora, debatia sobre os conteúdos, sobre referências consultadas, sobre as tarefas - conforme iam sendo cumpridas - e sobre a sua forma de apresentação na pasta. À medida que eram diagnosticadas necessidades a serem trabalhadas, o aluno era alertado e orientado e assim era levado a refletir sobre seus conhecimentos e/ou sobre sua prática. Entretanto, é importante ressaltar que as orientações procuraram sempre respeitar as particularidades de cada aluno, pois o objetivo maior era o pleno desenvolvimento da sua habilidade de avaliar o trabalho apresentado/efetivado e de refletir sobre suas próprias realizações, visto que "o ensino deve encorajar a reflexão ao vivido, buscando alcançar a excelência do cuidado ao ser humano, seja ele nosso paciente ou nossos alunos" (Pereira; Galperim, 1995, p. 202). 
À medida que o tempo foi passando e o trabalho crescendo, a satisfação dos alunos foi-se evidenciando. Na última semana do bloco prático, no final de novembro, a pasta entregue para análise final revelouse um excelente instrumento de comunicação entre docente e discente. Nossa idéia era que os estudantes conseguissem uma sólida base científica e, portanto, se tornassem mais críticos e reflexivos no decorrer do processo de construção da pasta de tarefas.

$\mathrm{O}$ que se manifestou nas entrelinhas foi que os estudantes queriam compilar todas as suas conquistas como futuros profissionais em sua pasta de tarefas. Os portfólios, assim, tinham riqueza de conteúdos e, também, beleza e primor na forma de apresentação. $\mathrm{O}$ aluno selecionou o que considerou importante para a sua aprendizagem, construiu e reconstruiu os trabalhos, possibilitando o cumprimento do objetivo geral da disciplina. Em 100\% das conclusões elaboradas, os alunos enfocaram a importância que o trabalho teve para o seu desempenho profissional, conforme revelam:

"Pude desenvolver atividades as quais contribuíram para o desenvolvimento do pensamento crítico, aprendizado em liderança e gerenciamento, prática do profissionalismo, aumento do conhecimento científico, tomada de decisão e resolução de problemas." (A13)

"Ao fazer o portfólio, foi possível planejar ações que interfiram em mudança e resolução de problemas, proporcionando um melhor direcionamento durante o estágio... foi possivel compreender o quanto se faz necessário rever a aplicabilidade dos planejamentos para se implantar mudanças e assim melhorar o desempenho do profissional de enfermagem." (A15)

Apenas três alunos - 15\% - relataram que a construção do portfólio foi cansativa e que necessitariam de um tempo maior para atingir os objetivos propostos, apesar de o processo vivenciado ter colaborado para o seu desenvolvimento profissional.

Não se trata de considerar o portfólio uma fórmula mágica como procedimento de avaliação e sim, de reconhecê-lo como uma prática que absorveu as características teórico-práticas da disciplina e possibilitou uma ação avaliativa processual, enriquecendo o aprendizado do aluno pelo aprofundamento das tarefas propostas e pela oportunização de novas vivências.

Foi consenso entre os alunos que a avaliação praticada, através do portfólio, levou-os a alcançar os objetivos da disciplina e, ainda, atingir seus próprios objetivos. Eles afirmam que: 
"Através deste método de trabalho foi possivel desenvolver disciplina e organização, com esses fatores o ato de gerenciar se torna mais simples e fácil de ser alcançado, sendo possível realizar uma auto-avaliação diária, melhorando o desenvolvimento e tornando o trabalho mais completo e, conseqüentemente, mais gratificante." (A6)

“Com a realização do portfólio foi possível obtermos uma noção geral do que compreende a disciplina de Administração em Enfermagem, onde o discente através de planejamentos estratégicos e operacionais pode sistematizar o seu estágio e desenvolver tudo aquilo que é necessário para o seu conhecimento e crescimento profissional." (A8)

“Com a elaboração da pasta foi possível agrupar as ações desenvolvidas no estágio de administração em enfermagem e ver que houve estímulo da criatividade, do pensamento crítico, ordenação das idéias através dos planejamentos, aumento do conhecimento científico e capacitação para a gerência da assistência." (A15)

No início da construção das pastas, os alunos apresentavam-se inseguros, solicitavam roteiros e modelos e, à medida que os trabalhos eram apresentados e discutidos, eles percebiam que não existia um formato predeterminado e reagiam, mostrando-se mais seguros, solicitando mais comentários. Parece ter havido uma compreensão da importância de trabalhar com seus próprios limites e possibilidades.

As tarefas propostas e o próprio processo de construção e retomada do portfólio parece ter deixado evidente para professores e alunos que

"para aprender, jamais é supérfluo compreender o sentido daquilo que se aprende. Para tanto, não basta que o saber seja inteligivel, assimilável. É necessário que esteja ligado a outras atividades humanas, que se compreenda porque foi desenvolvido, transmitido, porque é conveniente apropriar-se dele." (Perrenoud, 2000, p. 67)

A manifestação dos alunos foi singular e significativa:

"Assim como a lagarta se transforma em borboleta pelo esforço que ela faz para se livrar do casulo, nós também nos transformamos em profissionais melhores pelo esforço que fazemos para mostrar o nosso melhor desempenho. Nos descobrimos e nos assustamos com a nossa capacidade. Basta acreditar, tentar, arriscar! Para mim, realizar este trabalho, foi uma verdadeira superação dos limites que eu nunca pensara em vencer, ou mesmo lutar para vencê-los. Muito obrigado a todos que colaboraram para a realização desta pasta e muitas vezes sem imaginar, me ajudaram a crescer e me descobrir." (A8)

"Aprendi que não preciso ter medo do desconhecido, pois sou capaz de conquistar tudo o que quero e necessito, e que a cada dia que amanhece aprendo mais e consigo 
agilizar minhas ações [...] podem ter certeza que vou confiar sempre em mim, manter a calma e fazer sempre o melhor que posso, pois vocês me ensinaram que é a partir disto que serei mais feliz e terei muito sucesso." (A18)

"Dizer que estou encerrando este estudo ou concluindo este trabalho seria o mesmo que concordar em dizer que este é o fim do caminho [...] no entanto, a percepção que tenho é totalmente inversa. Sinto que este é o ponto de chegada para novos pontos de partida [...] o processo que culminou com o presente trabalho proporcionou intenso aprendizado afetivo e intelectual. Estando livre para escolher o que e como investigar, posso dizer de que os objetivos propostos foram atingidos. Não me resta a menor dúvida de que procurando fazer o melhor, estamos transmitindo graficamente algumas das muitas idéias que ocupam, nosso campo durante este percurso [...] as idéias aqui registradas tratam a expressão do nosso pensamento [...] os modelos de assistência apresentados aqui estão baseados em fundamentação teóricas que deram suporte para sua efetivação prática." (A20)

Os professores foram retratados como participantes ativos nos processos de ensino, aprendizagem e avaliação. As palavras dos alunos mostraram um amadurecimento acadêmico, conforme evidenciam suas palavras:

"Durante o estágio observou-se que a avaliação das docentes incentivou o aprimoramento dos cuidados de enfermagem ao paciente e direcionou as ações de gerenciamento de uma forma clara e objetiva." (A10)

"As dificuldades foram vencidas com força de vontade e com grande ajuda das docentes que me orientaram. Me sinto uma enfermeira, e esse sentimento é muito gratificante. Tenho certeza, mais do que nunca, de que escolhi a profissão certa."

"Eu confiei, pedi, sofri, às vezes me desiludi [...] obstáculos, empecilhos, falta de entusiasmo, passei sim, mas [...] sem dúvida a satisfação pessoal foi imensa e garantida." (A8)

Foi um aprendizado no decorrer do qual tornou-se possível constatar que, quando há envolvimento, respeito e reciprocidade entre professor e aluno, o professor consegue enxergar o aluno de forma global e real, favorecendo um desenvolvimento harmonioso, ainda que o aluno não consiga atingir a plenitude dos objetivos propostos, até porque "o docente de enfermagem não pode apenas transmitir o saber, mas deve se preocupar em incentivar a criação do saber" (Magalhães; Ide, 2001, p. 87).

Ainda, enquanto ferramentas de avaliação a subsidiar o portfólio, foram utilizadas fichas de análise de desempenho para registrar os compromissos e as possíveis alternativas para a superação de dificuldades. 
Então, o acadêmico tinha a oportunidade de se auto-avaliar e de articular a reconstrução do cotidiano de estágio participando do controle do processo de ensino, de aprendizagem e de avaliação. Formalmente foram realizados nas ficha de avaliação de desempenho três registros para cada período de estágio. Os momentos de análise e de discussão dos aspectos observados foram de grande interação e de significativa riqueza teórico-prática.

Ao consultar os registros feitos nas fichas e cruzar com as outras fontes de dados: portfólio e questionários, tornou-se possível constatar, mais uma vez, que a avaliação é o cenário ideal para questionar, para explorar, para debater e transformar a realidade do aluno e, ainda, redirecionar as práticas educativas.

O caminho do aprendizado precisa ser descoberto ou construído, por professores e alunos - em parceria e cumplicidade -, para poder ser percorrido e, cada vez mais, ser orientado e conduzido para a produção de novos conhecimentos e de novas formas de ação profissional.

A diversificação dos instrumentos de avaliação - na construção do portfólio - possibilitou a consecução de uma prática avaliativa comprometida com o diagnóstico e superação de dificuldades de aprendizagem, possibilitou aos partícipes do processo educativo refletirem sobre seus limites e possibilidades, estabelecendo formas de ação que permitissem tracejar percursos de superação; ainda, levou os professores a intervenções mais oportunas na promoção de aprendizagens mais significativas.

Salienta-se, mais uma vez, que a avaliação da aprendizagem deve trabalhar com a realidade vivenciada e os saberes essenciais ao bom desempenho profissional, para garantir que o estudante de enfermagem desenvolva habilidades para, refletindo - no confronto entre saberes e fazeres - decidir ações pertinentes a essa realidade.

\section{AS CONQUISTAS EFETIVADAS NO DECORRER DA CAMINHADA...}

Novos caminhos pedagógicos foram criados, analisados, discutidos e reorganizados, até porque "a forma como a avaliação foi realizada - pasta de tarefas -, assim como os recursos utilizados nas aulas e a forma democrática dos professores trabalharem conosco fizeram com que nós aprendêssemos mais" (A5).

Assim, a responsabilidade de elaborar a pasta de tarefas aliada à liberdade para a escolha das atividades que a comporiam, impulsionou o desejo de aprimorar conhecimentos, promovendo um despertar da criatividade, da autoconfiança e da independência e fazendo o medo da avaliação desaparecer ou ser, pelo menos, relativizado, pois o aluno sabia 
que a avaliação orientaria e facilitaria o seu aprendizado, confirmado a certeza de que

"por meio dos instrumentos de avaliação da aprendizagem, o educando poderá se autocompreender com a ajuda do professor, mas este também poderá se autocompreender no seu papel pessoal de educador, no que se refere ao seu modo de ser, às habilidade para a profissão, seus métodos, seus recursos didáticos, etc." (Luckesi, 1997, p. 176)

A avaliação formativa leva o professor a observar, a compreender e a sistematizar as intervenções pedagógicas necessárias para cada aluno, com o propósito de otimizar as aprendizagens: é a reflexão sobre a ação, fundamentada em prática avaliativa que tem "por finalidade principal o auxílio ao aluno, concebendo-o como responsável e participante do processo educativo, no sentindo de favorecer-lhe a tomada de consciência sobre suas conquistas e dificuldades e de apontar-lhe alternativas possíveis de evolução" (Hoffmann, 2000, p. 82).

"Foi diferente e acho que mais satisfatória. Pois eu tenho chances de melhorar, não é aquela coisa de que se errou, não tem como concertar. Aqui não, se não está bem, vamos discutir, ver onde posso melhorar e tentar desenvolver meu trabalho com melhor desempenho." (A10)

"Me senti estimulado ao perceber nas minhas dificuldades, que eu teria que melhorar e assim buscar o conhecimento para que eu pudesse prestar uma melhor assistência ao meu cliente." (A11)

"O positivo é que as coisas são discutidas previamente, Não deixando para apontar na última hora, quando não tem mais tempo para melhorar e mostrar que é capaz." (A13)

"O meu desempenho profissional no início era muito fraco não tinha segurança. Com as avaliações consegui acreditar em mim. Você sabe disso." (A9)

"A avaliação da disciplina de administração é uma avaliação progressiva, que nos dá o direito de mudarmos, e sabemos como estamos, diminuindo a ansiedade. As outras disciplinas fazem avaliação final, onde não temos como voltar para melhorar." (A17)

Dos vinte e um discentes, 90,4\% consideraram a experiência vivenciada positiva. Para $94,5 \%$ dos alunos, o processo de avaliação desencadeado favoreceu enormemente a promoção de alterações e superações no desempenho profissional, o que se evidencia quando afirmam que: 
"O meu desempenho profissional no início era muito fraco não tinha segurança. Com as avaliações consegui acreditar em mim." (A12)

"Me senti estimulada ao perceber nas minhas dificuldades, que eu teria que melhorar e assim buscar o conhecimento para que eu pudesse prestar uma melhor assistência ao meu cliente." (A16).

"Percebi que nem sempre uma crítica é para derrubar, mas sim para impulsionar a buscar novas alternativas, a tomada de decisões e ao aumento do conhecimento científico." (A18)

"O professor mostrava onde você tinha que melhorar. Eu tinha uma dificuldade de ver o paciente como um todo, mas com o auxílio do professor isso foi possivel acontecer." (A21)

No depoimento final, $71,56 \%$ dos alunos mostraram-se convencidos de que o processo de avaliação experienciado foi extremamente rico, uma vez que "proporcionou crescimento profissional para melhor vivenciar o dia-a-dia do enfermeiro e desenvolver um raciocínio coerente frente a cada nova situação que se apresente" (A15).

As práticas avaliativas implementadas ao longo do processo favoreceram o crescimento, o desenvolvimento e a aprendizagem por parte de todos os atores envolvidos, porque superaram barreiras geradas pelo individualismo e promoveram a cooperação, o trabalho coletivo e o compromisso ético.

Assim, avaliar, mantendo um olhar retrospectivo - para melhor analisar o trabalho efetivado - enquanto delineia possibilidades ao lançar também um olhar prospectivo, porque compromissado com o que há de vir, exige reconhecer que

"as diferentes formas de ser e de pensar dos educadores e dos educandos, poderá ultrapassar o individualismo e gerar a cooperação e a interdisciplinaridade na produção do conhecimento escolar. A cooperação envolve o exercício da descentração, a coordenação da diversidade de pontos de vista para se ampliar o entendimento sobre a realidade. A partir de diferentes jeitos de ser dos indivíduos é que se dá, de fato, a fluência da argumentação e contra-argumentação, a superação de enfoques absolutistas." (Hoffmann, 2000, p.25)

O processo avaliativo, portanto, deve gerar transformação e superação, deve ser positivamente marcante, porque ajuda o aluno a aprender e o professor a ensinar (Perrenoud, 1999). Essa percepção fica evidenciada na manifestação dos alunos, quando afirmam que 
"Todas as avaliações que foram feitas foram importantes para mim. Cada um delas me trouxe algo que pude refletir e assim melhorar. Durante as últimas avaliações pude perceber como cresci e quanto estava pronta para atuar como um boa profissional." (A11)

"Quando fui avaliado por postura, pensamento crítico e lógico o desempenho gerencial visto que aumentou minha auto-estima e me fez saber que sou capaz para atuar na enfermagem." (A16)

“Da $1^{\circ}$ para a $2^{a}$ avaliação fiquei muito contente com o salto que dei em gerenciamento e liderança e isso foi reconhecido. Muito Bom! O relacionamento com docentes e diversos incentivos e estímulos recebidos. Ouvir na última avaliação que a docente se sentia segura em relação ao meu profissionalismo e liderança da equipe foi especial." (A20)

Ensinar, aprender, avaliar são partes que integram um mesmo processo, apresentando-se intimamente imbricadas, principalmente porque a aprendizagem nunca é simples e direta, mas

"procede por ensaios, por tentativas e erros, hipóteses, recuos e avanços; um individuo aprenderá melhor se o seu meio envolvente for capaz de lhe dar respostas e regulações sob diversas formas: identificação dos erros, sugestões e contra sugestões, explicações complementares, revisão das noções de base, trabalho sobre o sentido da tarefa ou a auto confiança." (Perrenoud, 1993, p. 76)

Pelas manifestações dos alunos ficou evidente que compreenderam a importância do processo de avaliação e, mais, esqueceram o medo que sentiram ao utilizarem os dados e informações advindos dos instrumentos e práticas avaliativas para a busca de novos conhecimentos no aperfeiçoamento da prática profissional.

\section{CONSIDERAÇÕES FINAIS}

O caminho percorrido permitiu a confirmação daquilo que intuíamos: de que ao trabalhar com a avaliação como processo, haveria uma potencialização no desenvolvimento dos alunos, possibilitando uma aprendizagem mais dinâmica, menos traumática, voltada para a construção de um profissional mais reflexivo e comprometido com uma sociedade em constante metamorfosear.

O trabalho não teve a pretensão de afirmar a melhor maneira de avaliar os alunos, mas sim de refletir como o cotidiano acadêmico pode mudar com práticas pedagógicas que possibilitem a formação de um 
profissional preparado para o superar dificuldades, com capacidade de exercitar a reflexão na ação, sobre a ação e sobre a reflexão na ação.

Assim, pensar uma nova forma de compreender e atuar na formação do profissional de enfermagem é buscar mudanças que estejam relacionadas com o mundo do conhecimento e o mundo do trabalho, com compromissos éticos, sociais e políticos.

Nessa perspectiva é fundamental o reconhecimento do direito e da responsabilidade de professores e estudantes, para a construção de um espaço de liberdade e de interação. Avançar nesse tema significou buscar novos estilos de ensinar e de aprender em enfermagem, significou trabalhar no processo de formação possibilitando o aprofundamento do núcleo de conhecimentos do aluno.

Os caminhos aparentemente nada mais eram que um emaranhado de estratégias que, no decorrer do ano, foram se encaixando e produzindo resultados. No entanto, o importante não era somente desvendar estratégias, mas, sim e também, edificar um processo de avaliação diferente no decorrer do qual a relação entre professor e aluno fosse ampliada e intensificada contribuindo para que o aluno se libertasse do medo e reduzisse sua ansiedade, em face da compreensão da avaliação enquanto um espaço e um tempo de auto-superação e crescimento.

Os alunos precisam de limites, mas também de liberdade e de orientação, o que pressupõe o caminhar conjunto, de docentes e discentes, rumo à consecução de uma prática avaliativa cujo compromisso maior seja determinar as circunscrições para enunciar as superações necessárias.

É fundamental que o professor compreenda que deve existir uma conexão entre o momento da avaliação e o processo de ensino e aprendizagem, assim como é fundamental que o profissional compreenda que deve existir conexão entre o exercício da avaliação - no cotidiano de trabalho - e a superação das dificuldades e problemas que se apresentam. A proposta foi formar profissionais que buscassem o aprimoramento, que questionassem e criticassem as situações vivenciadas em prol de uma assistência de enfermagem com qualidade.

A avaliação, indo além do que os olhos vêem, estabelecendo as reais necessidades do aluno para um aprendizado sem traumas, constitui fator de realimentação contínua no decorrer do ensinar, do aprender e do aperfeiçoar a prática profissional.

A intenção foi mudar o conceito de avaliação pela mudança do processo de avaliar, foi levar o aluno a refletir à medida que avança na edificação do conhecimento, auxiliando-o na descoberta de novos conhecimentos e incitando-o a aprimorar sua atuação. 
Assim, foi possível constatar que as tarefas propostas ou coletivamente elaboradas para consecução do processo de avaliação levaram o aluno a subir a escada do conhecimento ultrapassando etapas, superando obstáculos e buscando continuamente a sua formação profissional. A participação do aluno nessa construção é favorecida quando o professor promove momentos de desafio e reflexão, incentivando o aluno a formular e a reformular seus próprios conceitos (Hoffmann, 2000a), quando professor e aluno caminham juntos e crescem juntos. É notório que enveredar por esses caminhos não é uma missão simples. É necessário disposição para não parar jamais e para recomeçar sempre que houver necessidade.

\section{REFERÊNCIAS BIBLIOGRÁFICAS}

ANGELO, M. Vivendo uma prova de fogo: as experiências iniciais da aluna de enfermagem. São Paulo, 1989. Tese (Doutorado em Psicologia Escolar) Instituto de Psicologia, Universidade de São Paulo.

BARDIN, L. Análise de conteúdo. Lisboa: Ed 70, 1977.

GARDNER, Howard. Inteligências múltiplas. A teoria na prática. Porto Alegre: Artes Médicas, 1995.

GEIB, Lorena Teresinha Consalter et al. Os rituais de poder na educação formal do enfermeiro. Revista Texto $\mathcal{E}$ Contexto - Enfermagem. Universidade de Santa Catarina. Florianópolis, v.8, n.80-92, jan./abr. 1999.

HADJI, Charles. A avaliação desmistificada. Porto Alegre: Artmed, 2001.

HOFFMANN, J. M. L. Pontos e contrapontos: do pensar ao agir em avaliação. 4. ed. Porto Alegre: Medicação, 2000.

Avaliação: mito e desafio: uma perspectivas construtivista. 29. ed. Porto Alegre: Mediação, 2000a.

KESTENBERG, C. C. F. Avaliação o caos nosso de todo dia. Rio de Janeiro: Cultura Médica, 1985.

LUCKESI, C. Avaliação da aprendizagem escolar. 2. ed. São Paulo: Cortez, 1997.

MAGALHÃES, L. M. T; IDE, C. A. C. O ensino superior em enfermagem e o desafio da mudança: os referenciais de um novo processo de formação. In: IDE, C. A. C.; DOMENICO, E. B. L. (orgs.). Ensinando e Aprendendo um novo estilo de cuidar. São Paulo: Atheneu, 2001. p. 83-105. 
MEDEIROS, Roseana Maria. As interações em sala de aula e a construção das competências em enfermagem: um debate para além do tecnicismo. In: MEDEIROS, Roseana Maria; STÉDILE, Nilva Lúcia Rech; CLAUS, Suzete Marchetto (orgs.). Construção de competências em enfermagem. Caxias do Sul: UDUCS, 2001. p.11-91.

PECCI, J. C. O ramo de hortênsias. São Paulo: Círculo do Livro, 1986.

PEREIRA, R. C. J.; GALPERIM, M. R. O. Cuidando-ensinandopesquisando. In: WALDOW, V. R.; LOPES, M. J. M.; MEYER, F. E. (orgs.) Maneiras de cuidar, maneiras de ensinar: a enfermagem entre a escola e a prática profissional. Porto Alegre: Artes Médicas, 1995. p.189-203.

PERRENOUD, P. Avaliação: da excelência à regulação das aprendizagens: entre duas lógicas. Porto Alegre: Artes Médicas, 1999.

Médicas, 2000.

Pedagogia diferenciada: das intenções à ação. Porto Alegre: Artes - Práticas pedagógicas, profissão docente e a formação: perspectivas sociológicas. Lisboa: D. Quixote, 1993.

SORDI, Mara. Regina Lemes de. A prática de avaliação do ensino superior: uma experiência na enfermagem. São Paulo: Cortez, 1995.

Recebido em: dezembro 2003 Aprovado para publicação em: março 2004 
